\title{
Some medical associations see modest growth despite challenges
}

\author{
[ Cite as: CMAJ 2018 January 8;190:E32-3. doi: 10.1503/cmaj.109-5530
}

Posted on cmajnews.com on Dec. 5, 2017.

$\mathrm{T}$ he percentage of doctors joining national medical associations is far below historical peaks in many countries, but some associations have seen modest growth, or at least held steady, through physician advocacy and digital innovation.

The Canadian Medical Association (CMA)'s numbers are high compared to the international picture. Some 87000 members, or $80 \%$ of Canadian doctors, belong to the CMA, which celebrated its 150th anniversary this year. Since 2009, the association has grown $18 \%$, according to CEO Tim Smith.

South of the border, the American Medical Association represents 240000 doctors, or about $28 \%$ of the physician workforce. For the past six years, the organization has seen membership grow $1 \%-3 \%$ per year. "That's in distinction from what has happened the previous 30 years," says Dr. James Madara, CEO and executive vice-president of the AMA.

Australia's medical association represents almost 30000 members, or nearly $30 \%$ of the medical profession. "It's held pretty steady for the last four or five years," says Anne Trimmer, the organization's secretary general.

Still, many challenges remain. Before the slight rebound in recent years, most medical associations watched their numbers drop for several decades. In the 1950s, $75 \%$ of American doctors were members of the American Medical Association. The Australian Medical Association had its "heyday" a half-century ago, "when almost all medical practitioners were members," noted one health scholar.

Even the CMA, though it boasts a much stronger market share, has expressed

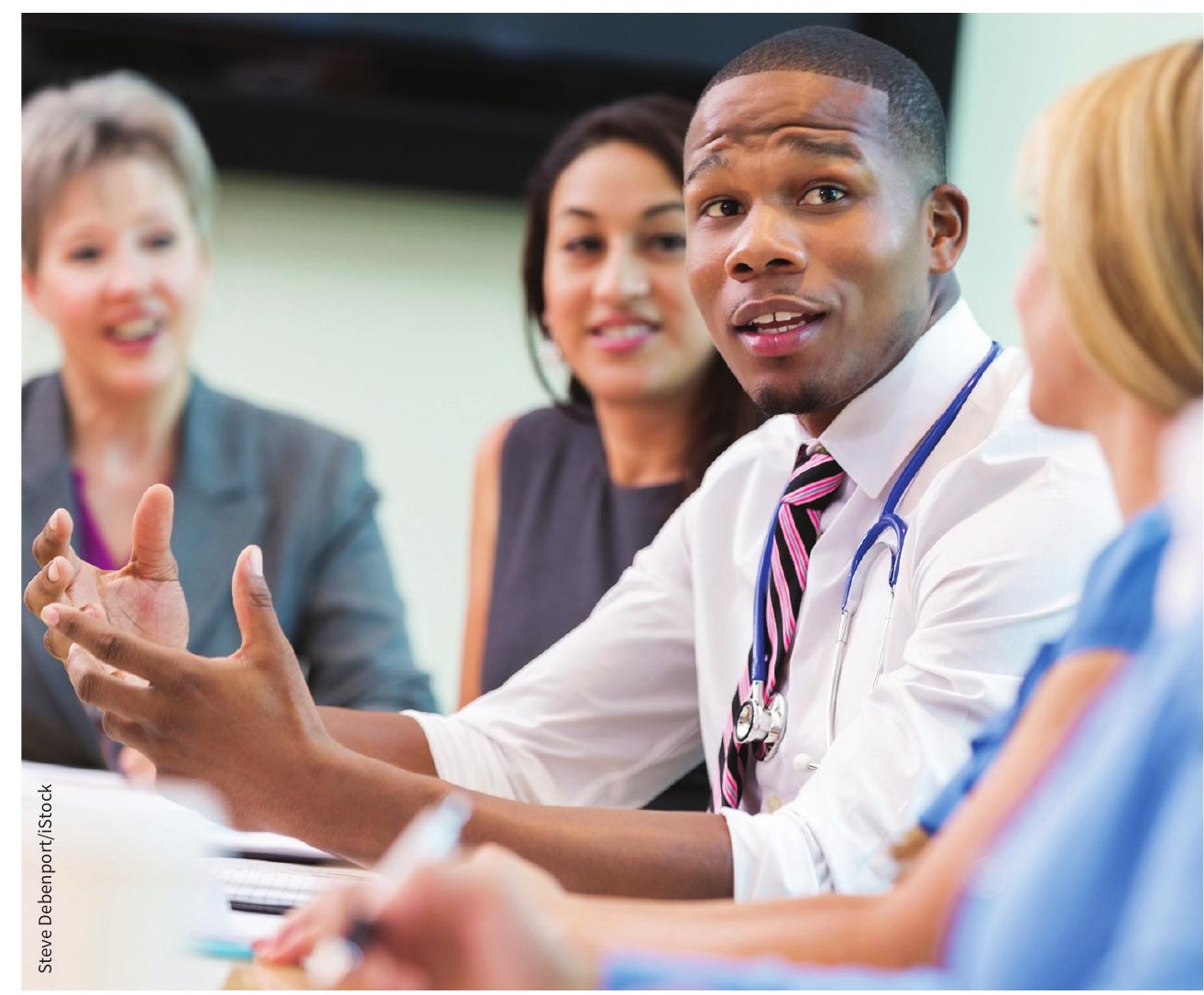

National medical associations have turned to advocacy and digital innovation to retain and attract members.

concerns about remaining relevant in the modern age of medicine. "The Internet, with its ease of access to information and social media platforms, has replaced many of the benefits that associations like ours used to offer," Dr. Brian Brodie, chair of the CMA board of directors, said at the association's annual meeting in August.

A major issue is the difficulty of finding common ground among doctors in disparate specialties, geographic locations, practice set-ups and life-stages. Dean West, president of the Association Labora- tory, a Chicago-based consulting firm for professional associations, says that today's doctors have a plethora of choices of organizations that can represent them, from specialty organizations to large practice networks to advocacy groups. "These didn't exist for doctors 30 years ago," he says. Almost $80 \%$ of US physicians are members of specialty societies.

Politics and labour disputes can also affect membership rates. The American Medical Association lost some members because of its position in favour of 
Obamacare. According to Madara, however, more doctors were attracted to the AMA because of its strong advocacy to preserve insurance for those previously uninsured. In the United Kingdom, many junior doctors used social media to declare they were cancelling their British Medical Association memberships because of its unwillingness to support them in a labour dispute with the government.

Amid this complicated landscape, medical associations should figure out what doctors are getting from competing organizations and look for gaps, suggests West. For instance, the CMA's growth has been attributed in part to its popular financial services, such as the financial planning and trust services provided by MD Financial. The CMA's focus on physician wellness has been another recent attraction, says Smith.

As for the American Medical Association, Madara credits the association's focus on technological innovation as one major reason behind the membership growth. In October, for example, it launched a data model for electronic medical records to make it easier to share information. The Australian Medical Association is also focusing on increasing its digital services, so that members can provide input on policies or seek time-sensitive career advice online.

Wendy Glauser, Toronto, Ont. 